\title{
Parental effects in Plantago lanceolata L. II. Manipulation of grandparental temperature and parental flowering time
}

\author{
ANDREA L. CASE †, ELIZABETH P. LACEY* \& ROBIN G. HOPKINS \\ Department of Biology, University of North Carolina at Greensboro, Greensboro, NC 27412-5001, U.S.A.
}

\begin{abstract}
In an experimental study of Plantago lanceolata L., postzygotic environmentally induced parental effects were (1) transmitted across generations, (2) genotype-specific, and (3) mediated by natural differences in flowering phenology. Individuals were cloned, hand-pollinated and allowed to mature seed at one of two temperatures. Second-generation plants were induced to seed-set at four times during the flowering season. The effects of grandparental temperature (GPT), parental flowering time (PFT) and maternal family (MFAM) on seed size, germination, leaf area and allometry, flowering time and male sterility in third generation plants were then measured. GPT significantly affected all adult traits and did so more strongly than and often independently of seed weight and germination. The data suggest that heritable GPT effects arise from gametophytic selection or genomic modification. Significant GPT $\times$ MFAM interactions were detected for seed weight, leaf area, flowering time, and male sterility. Such genotype-specific responses are necessary if parental temperature is to influence the evolutionary divergence of life history and breeding patterns in populations growing in different temperature regimes. PFT affected leaf area and percentage germination. Natural changes in photoperiod but not temperature may explain the observed PFT effects on germination.
\end{abstract}

Keywords: flowering phenology, gametophytic selection, intergenerational plasticity, life history evolution, parental temperature effects, Plantago lanceolata.

\section{Introduction}

Two factors are likely to influence the evolutionary importance, or magnitude, of environmentally induced parental effects in natural plant populations. The first is the ability of the natural environment to produce an effect. The second is the persistence of such effects, both into the adult phase of a plant's life cycle and across generations. Few studies have been conducted in field settings, where naturally induced parental effects could be measured (Antonovics \& Schmitt, 1986; Bière, 1991; Schmitt et al., 1992). Likewise, few studies have looked for effects beyond the seeding stage (e.g. Roach \& Wulff, 1987; Miao et al., 1991a,b; Wulff \&

\footnotetext{
*Correspondence.

†Present address: Department of Botany, University of Toronto, Toronto, Ontario, Canada M5S 3B2.

$\ddagger$ Present address: Department of Foods and Nutrition, University of North Carolina at Greensboro, Greensboro, NC 27412, U.S.A.
}

Bazzaz, 1992). Even fewer studies have demonstrated that environmentally induced effects are truly intergenerational, i.e. heritable (e.g. Durrant, 1962; Alexander \& Wulff, 1985; Miao et al., 1991a,b; Schneeberger \& Cullis, 1991; Wulff \& Bazzaz, 1992; Platenkamp \& Shaw, 1993). Often the environment in the first generation is confounded with the embryonic environment of the second generation. Thus, offspring phenotypic responses to parental environments could represent either inter- or intragenerational responses.

To learn more about the natural induction of environmentally induced parental effects and their intergenerational persistence, we conducted a threegeneration experiment with Plantago lanceolata L. The study was a continuation of a two-generation experiment that measured the effects of parental temperature on offspring life history traits in $P$. lanceolata (Lacey, 1996). In Lacey's experiment, parents were grown under two temperature regimes to measure the effects of pre- and postzygotic 
temperature in the first generation on several life history traits in the second generation. Prezygotic temperature is defined as the temperature prior to fertilization and seed-set. Postzygotic temperature is defined as the temperature during fertilization and seed-set. Low parental temperature increased seed weight, reduced germination and offspring growth rate, and accelerated onset of reproduction in offspring when compared to the effects of high parental temperature. Postzygotic temperature influenced offspring phenotype much more than did prezygotic temperature. The postzygotic effects may have been mediated by the maternal parent, or the embryonic environment may have directly altered the phenotypes of traits expressed later in the life cycle. In our experiment, we examined the effects of temperature in the first generation, and of flowering time in the second generation, on individuals in the third generation. Traits measured were seed weight, percentage germination, leaf area, leaf allometry, onset of flowering, and male sterility.

Four questions were addressed. (1) Can postzygotic effects be transmitted across generations? (2) Are adult as well as juvenile traits affected in the third generation, and if so, does grandparental temperature influence adult traits independently of the effect of temperature on juvenile traits? (3) Are responses of the third generation to grandparental temperature genotype-specific, as indicated by significant $\mathrm{G} \times \mathrm{E}$ (ancestral) interactions? If families differ in their responses to grandparental temperature, then natural populations growing in habitats that, on average, differ in their temperature regimes might evolve in different ways because of environmentally induced parental effects (Lacey, 1996). (4) Can environmental variation that is associated with natural differences in flowering phenology produce parental effects? We also tested for the independent effects of temperature and photoperiod in mediating parental flowering time effects.

\section{Materials and methods}

\section{Study species}

Plantago lanceolata L. (Plantaginaceae), ribwort plantain, is a weedy, cosmopolitan, herbaceous perennial plant species. It grows vegetatively as a rosette and produces flowers on 'spikes' (compact inflorescences) that arise from axillary buds. The flowering season in North Carolina extends from May through August. The species is protogynous, gynodioecious, and self-incompatible (Ross, 1973; van Damme, 1983).

\section{The first generation}

Details of the selection, growing conditions and crossing design of plants used for the first generation are given by Lacey (1996). Features relevant to this experiment are briefly summarized here. In 1989, clones of plantain individuals from two populations were randomly assigned to one of two growth chambers that differed only in their temperature regime: low $=15^{\circ} \mathrm{C}$ nights $/ 20^{\circ} \mathrm{C}$ days, high $=20^{\circ} \mathrm{C}$ nights $/$ $26^{\circ} \mathrm{C}$ days (Fig. 1). These regimes approximate average monthly temperatures for May and July, respectively, in North Carolina (Teramura et al., 1981).

We reciprocally crossed each genotype from one population with each genotype from the other population. For the experiment reported here, both parents for a given cross and their seeds grew and

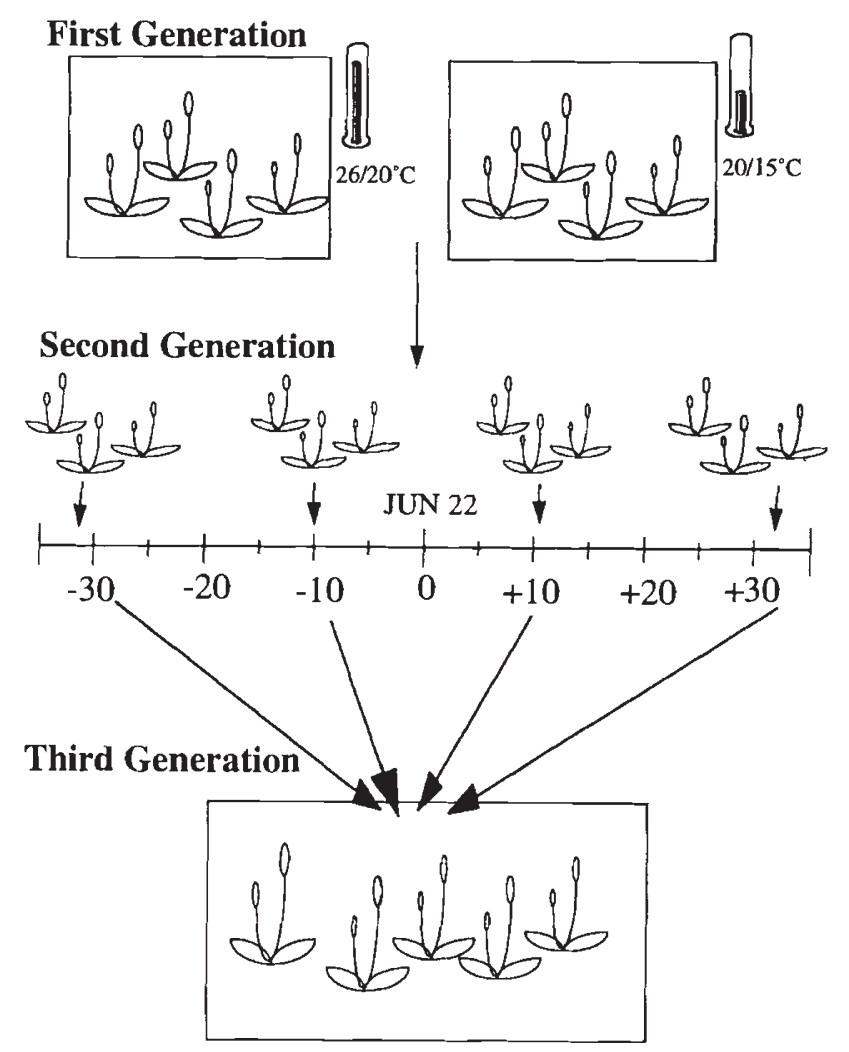

Fig. 1 Experimental design of a test for temperature effects in Plantago lanceolata. First generation: replicate clones of four genotypes were grown and crossed within temperature treatments. Second generation: progeny from both temperature treatments were induced to set seed outside twice before and twice after the summer solstice (June 22). Third generation: offspring were grown in a single controlled environment (see text for details). 
matured, respectively, under either high or low temperature. We refer to these temperature treatments as grandparental temperature (GPT) treatments. Four reciprocal crosses were used for our experiment because there were enough seeds remaining in both temperature treatments after two other experiments to complete the experiment described here. Also, each cross had a unique combination of maternal and paternal parents, which maximized the genetic diversity that we could accommodate in our experiment. We refer to these four crosses as maternal families (MFAMs).

\section{The second generation}

In 1991, stored seeds from the four MFAMs within each temperature treatment were assigned randomly to four parental flowering time (PFT) treatments (Fig. 1). Offspring were induced to flower on either May 22 , June 12 , July 3 or July 24 . Temperature was expected to increase monotonically from the first to the last flowering-time treatment. Plants induced to flower on June 12 and July 3, close to the summer solstice, would produce seeds under long day lengths, whereas plants induced to flower on May 22 and July 24 would produce seeds under shorter day lengths.

Seeds in each PFT treatment were sown 12 weeks prior to the desired flowering time so that plants in all PFT treatments would resemble each other in size and developmental stage at flowering. Plants were grown individually in pots filled with Terra-lite Metromix in a Conviron growth chamber $\left(20^{\circ} \mathrm{C}, 16 \mathrm{~h}\right.$ nights $/ 26^{\circ} \mathrm{C}, 8 \mathrm{~h}$ days; $\frac{1}{2}$-strength Hoagland's solution every second day). Six weeks prior to each flowering time, we moved plants to a greenhouse $\left(20^{\circ} \mathrm{C}, 8 \mathrm{~h}\right.$ nights $/ 26^{\circ} \mathrm{C}, 16 \mathrm{~h}$ days; $\frac{1}{2}$-strength Hoagland's solution once per day) to induce flowering.

At each flowering date, we transplanted three replicate full-sibs per MFAM per GPT to an outdoor plot in Greensboro, NC. Just before transplanting, we clipped the upper half of all leaves on each plant and all but 4-6 reproductive spikes at or near anthesis. Two to three spikes were used for this experiment; the remainder were used for another experiment. Once outside, all plants were fertilized twice weekly and watered as needed to minimize nutrient or water stress.

Plants were randomly assigned to locations identified prior to May 22. Each plant, in its pot, was sunk into one of two holes at each location. These plants served as maternal parents. To reduce the confounding of PFT with paternal genotype effects, we placed a potential pollen donor in the other hole at each location. All potential pollen donors had been grown with the maternal parents under the same growing conditions. A unique set of full-sibs was used as pollen donors for each MFAM across all PFT treatments. Some plantains flowering in the area surrounding our experimental plot probably also served as pollen donors. Plants were allowed to flower and set seed naturally. Brown spikes were harvested and were stored by replicate sib for each GPT $\times$ PFT combination in coin envelopes in the laboratory. Eighty-two of the 96 replicate $\mathrm{sib} \times \mathrm{GPT} \times \mathrm{PFT}$ combinations produced third generation seeds, which we refer to as 'offspring'.

\section{The third generation}

In 1992, we weighed six seeds in each replicate sib $\times$ GPT $\times$ PFT combination to the nearest $0.1 \mathrm{mg}$ on a CAHN-31 microbalance. Seeds were then sown in pots filled with Terra-lite Metromix, and the pots were placed randomly in a growth chamber. Two seeds for each replicate sib $\times$ GPT $\times$ PFT combination were assigned to each pot. We recorded germination at 12 and 20 days postplanting (dpp). On day 20 we selected the three largest seedlings per replicate sib $\times$ GPT $\times$ PFT combination for further measurements. Each was grown in its own pot. At 27-31 and 55-57 dpp, we recorded leaf number and measured the length and width of the longest leaf on each plant. At 93-95 dpp, plants were censused for presence of flowering spikes. Length and width of the longest leaf were measured again at $\sim 127 \mathrm{dpp}$. Male sterility was recorded when plants reached anthesis. A plant was considered to be male sterile if it failed to produce anthers.

Offspring were grown under the following photoperiodic conditions: $0-55 \mathrm{dpp}: 15^{\circ} \mathrm{C}, 16 \mathrm{~h}$ nights/ $20^{\circ} \mathrm{C}, 8 \mathrm{~h}$ days; $55-83 \mathrm{dpp}: 20^{\circ} \mathrm{C}, 10 \mathrm{~h}$ nights $/ 26^{\circ} \mathrm{C}$, $14 \mathrm{~h}$ days. The photoperiod was then changed to $8 \mathrm{~h}$ nights $/ 16 \mathrm{~h}$ days to induce flowering. We watered each pot daily for two weeks after planting and three times per week thereafter. Twenty-three days after planting, we began fertilizing three times per week with $1 / 4$ strength Hoagland's fertilizer. After $55 \mathrm{dpp}$, we fertilized with $1 / 2$ strength Hoagland's three times per week and watered on all other days.

\section{Data analysis}

ANOVAR and ANCOVAR (GLM procedures; SAS Institute, 1985) were performed to examine the effects of GPT, PFT, and MFAM on seed weight, germination at $20 \mathrm{dpp}$, size at 27 and $55 \mathrm{dpp}$, onset of flowering and leaf allometry. Analyses were performed on the 
mean values for each replicate sib. Thirty of the 32 cells in the factorial design contained at least two mean values. Type III sums of squares are reported. All independent factors were treated as 'fixed', including MFAM because of the limited number of families used and because of the selection criteria described earlier. Germination and flowering time percentages were arcsine transformed for the analyses. Estimated total leaf area was used as our measure of plant size (Lacey, 1996). Leaf allometry was expressed as width/length of longest leaf.

Male sterility was analysed using the CATMOD procedure (SAS Institute, 1985). The probability of producing perfect flowers was the response variable. Because CATMOD does not tolerate zero cells in the analysis, we ran the procedure several times replacing zeros with values from $0.5-0.000005$. The $P$ values stabilized at values $\leq 0.005$, so the results of the analysis using a value of 0.005 are reported here.

For each variable except seed weight, we performed at least two analyses, with and without juvenile traits as covariates. We considered seed weight and percentage germination to be juvenile traits; leaf area, onset of flowering, male sterility and leaf allometry were treated as adult traits. This procedure allowed us to determine whether our independent factors affected germination and the adult traits directly and/or indirectly via their effects on juvenile traits.

For traits affected by PFT, we performed twoway ANOVAR tests to see if temperature and photoperiod could have caused the PFT effects. Two levels of photoperiod were created: longer days (PFT 2 and 3) and shorter days (PFT 1 and 4). The four temperature values, nested within the photoperiods, corresponded to the four PFTs. Temperature values were determined by averaging the mean daily temperatures at the Greensboro airport for the three weeks following transplantation in each PFT treatment. Seed maturation is largely completed in three weeks.

\section{Results}

\section{Grandparental temperature - main effects}

GPT strongly affected the adult traits: leaf area at $55 \mathrm{dpp}$, flowering at 94 days, and leaf allometry after $127 \mathrm{dpp}$ (Table 1). GPT marginally affected leaf area in the ANOva (d.f. $=3, P=0.0757$ ), and significantly affected it with covariates included (Table 1 , $P=0.03$ ). Mean leaf area of offspring in the low GPT group was 7 per cent higher than mean area in the high GPT group (low GPT mean $\pm \mathrm{SE}=$ $226.4 \pm 5.7 \mathrm{~cm}^{2}$; high GPT mean $\pm \mathrm{SE}=210.8 \pm 5.8$ $\mathrm{cm}^{2}$ ). Leaf area was marginally correlated with seed weight.

GPT significantly affected flowering without covariates (ANOVA, $P=0.049$ ) and marginally affected it with covariates (Table 1; ANCOVA, $P=0.064$ ).

The low GPT group showed a 16 per cent increase in number of plants flowering (mean percentage flowering at high and low GPT: 57 per cent and 66.3 per cent, respectively).

GPT did not affect leaf allometry at 27 or $55 \mathrm{dpp}$ but did so by 127 dpp (ANOVA, $P=0.022$; Table 1, ANCOVA, $P=0.037$ ). Leaves of plants in the low GPT group were, on average, longer and thinner

Table 1 Parental and grandparental effects on offspring traits in Plantago lanceolata

\begin{tabular}{|c|c|c|c|c|c|c|c|}
\hline Source & d.f. & Seed weight & $\%$ Germ. & Leaf area $(27 \mathrm{dpp})$ & Leaf area $(55 \mathrm{dpp})$ & $\%$ Flowering & Allometry \\
\hline PFT & 3 & 0.042 & $0.435 \dagger$ & 21.66 & $7775 * * *$ & 0.155 & $<0.0001$ \\
\hline GPT & 1 & 0.007 & 0.281 & 6.76 & $4779 *$ & $0.758 \dagger$ & $0.0004 *$ \\
\hline MFAM & 3 & 0.065 & 0.109 & 9.84 & 82 & 0.212 & 0.0002 \\
\hline $\mathrm{PFT} \times \mathrm{GPT}$ & 3 & 0.023 & 0.038 & 3.95 & 1466 & 0.277 & 0.0002 \\
\hline $\mathrm{PFT} \times \mathrm{MFAM}$ & 9 & 0.028 & 0.047 & 20.14 & 1003 & 0.096 & $0.0002 \uparrow$ \\
\hline GPT $\times$ MFAM & 3 & $0.135 \dagger$ & 0.175 & 35.50 & 630 & $1.102^{* *}$ & $<0.0001$ \\
\hline $\mathrm{PFT} \times \mathrm{GPT} \times \mathrm{MFAM}$ & 9 & 0.045 & 0.240 & 41.59 & 870 & 0.173 & $<0.0001$ \\
\hline Seed weight & 1 & - & $1.261^{* * *}$ & $203.37^{* *}$ & $2705 \dagger$ & 0.024 & $<0.0001$ \\
\hline$\%$ Germination & 1 & - & - & 11.30 & $4842 *$ & 0.215 & $<0.0001$ \\
\hline Leaf area ( $27 \mathrm{dpp})$ & 1 & - & - & - & $\ldots$ & $0.618 \dagger$ & - \\
\hline
\end{tabular}

Values given as mean squares. Fixed-model analyses of variance and covariance of offspring traits. Covariates include seed weight, percent germination at $20 \mathrm{dpp}$, and total leaf area estimated at $27 \mathrm{dpp}$. A dashed line for a covariate indicates that it was not included in the analysis.

PFT, parental flowering time; GPT, grandparental temperature; MFAM, maternal family.

$\dagger P<0.10,{ }^{*} P<0.05,{ }^{*} P<0.01,{ }^{* *} P<0.001$. 
(i.e. had a lower index value) than were leaves in the high GPT group (Table 2). The difference in index value was $\sim 9$ per cent. Changes in both leaf length and width appear to have contributed to this allometric difference (Table 2). GPT marginally affected leaf length (ANOVA, $P=0.091$ ) and width (ANOVA, $P=0.0885)$ at $127 \mathrm{dpp}$.

Table 2 Mean length and width of longest leaf $(\mathrm{cm})$ and leaf allometry index (LAI) of offspring in response to grandparental temperature (GPT) treatments in Plantago lanceolata $(n=41)$

\begin{tabular}{lcccc}
\hline Variable & DPP & GPT & Mean & SE \\
\hline Length & 27 & H & 6.87 & 0.19 \\
& & L & 6.85 & 0.25 \\
& 55 & H & 11.82 & 0.16 \\
& & L & 12.18 & 0.17 \\
& 127 & H & 47.20 & 0.88 \\
Width & & L & 48.90 & 0.61 \\
& 27 & H & 1.059 & 0.026 \\
& & L & 1.062 & 0.035 \\
& 55 & H & 1.978 & 0.035 \\
& & L & 2.012 & 0.033 \\
& 127 & H & 2.224 & 0.063 \\
LAI & & L & 2.129 & 0.062 \\
& 27 & H & 0.156 & 0.003 \\
& & L & 0.158 & 0.004 \\
& 55 & H & 0.168 & 0.004 \\
& & L & 0.167 & 0.004 \\
& 127 & H & 0.048 & 0.002 \\
& & L & 0.044 & 0.001 \\
\hline
\end{tabular}

DPP, days postplanting; LAI, width/length of longest leaf; $\mathrm{H}$, high; L, low.

Table 3 Parental and grandparental effects on the percentage of male steriles in Plantago lanceolata

\begin{tabular}{lcc}
\hline Source & d.f. & $\chi^{2}$ \\
\hline PFT & 3 & 1.32 \\
GPT & 1 & 0.47 \\
MFAM & 3 & $16.65^{* * *}$ \\
PFT $\times$ GPT & 3 & $7.90^{* *}$ \\
PFT $\times$ MFAM & 9 & $16.47^{*}$ \\
GPT $\times$ MFAM & 3 & $18.57^{* * *}$ \\
PFT $\times$ GPT $\times$ MFAM & 9 & $20.37^{* *}$ \\
\hline
\end{tabular}

Categorical analysis of the percentage of male steriles in third generation plants in which the response variable was the probability of producing hermaphroditic flowers. Zero values were replaced with 0.005 for the analysis (see text). Abbreviations defined in Table 1.

${ }^{*} P<0.10,{ }^{* *} P<0.05,{ }^{* * *} P<0.01$.

\section{Genotypic-specific responses to GPT}

MFAMs differed in their responses to GPT for four traits: seed weight, leaf area at $27 \mathrm{dpp}$, flowering at $94 \mathrm{dpp}$ and male sterility (Tables 1 and 3 ). The GPT $\times$ MFAM interaction was marginally significant for seed weight $(P=0.057)$. It was significant for leaf area without covariates (ANOvA, d.f. $=3$, $P=0.0397$ ) but not with covariates (Table 1). The interaction for flowering was highly significant without and with covariates (ANOVA, $P=0.001$; Table 1).

For all traits the rank order of MFAMs changed with GPT (Fig. 2a-d). The two MFAMs that produced the heavier seeds and larger plants and the two, albeit different, MFAMs that had higher male sterility at low GPT produced the lighter seeds and smaller plants and showed lower male sterility at high GPT. The difference in leaf area between the two groups of MFAMs was $\sim 7$ per cent. Rank order of plants flowering also changed. For one MFAM, only 67 per cent of the plants flowering in the high GPT group flowered in the low GPT group. In contrast, in another MFAM twice as many plants flowered at low GPT as did so at high GPT. In addition to rank order, interfamily variance changed with GPT for seed weight and male sterility (Fig. 2a,d).

\section{Flowering time effects}

Parental flowering time affected only offspring germination and leaf area at $55 \mathrm{dpp}$ (Table 1). It marginally affected germination with and without covariates (ANCOVA, $P=0.067$; ANOVA, $P=0.072$ ). Offspring of parents that flowered in mid-June (PFT2) showed the highest germination (Fig. 3a). Its effect on leaf area was highly significant with and without covariates (Table 1). The plants which flowered latest (PFT 4) produced the smallest offspring (Fig. 3b).

Differences in germination and leaf area were associated more often with changing photoperiod than with temperature. This may have been a consequence of 1991 temperatures, which were warmer than average and varied little across PFT treatments (Fig. 3c). Germination and leaf area were 13 per cent and 10 per cent, respectively, higher in the longer photoperiod group (germination: d.f. $=1$, $P=0.039$; leaf area: d.f. $=1, P=0.0006$ ). Temperature did not significantly affect germination (d.f. $=2$, $P>0.10$ ). It did affect leaf area (d.f. $=2$, $P=0.0001)$. Under shorter days, smaller leaf area 

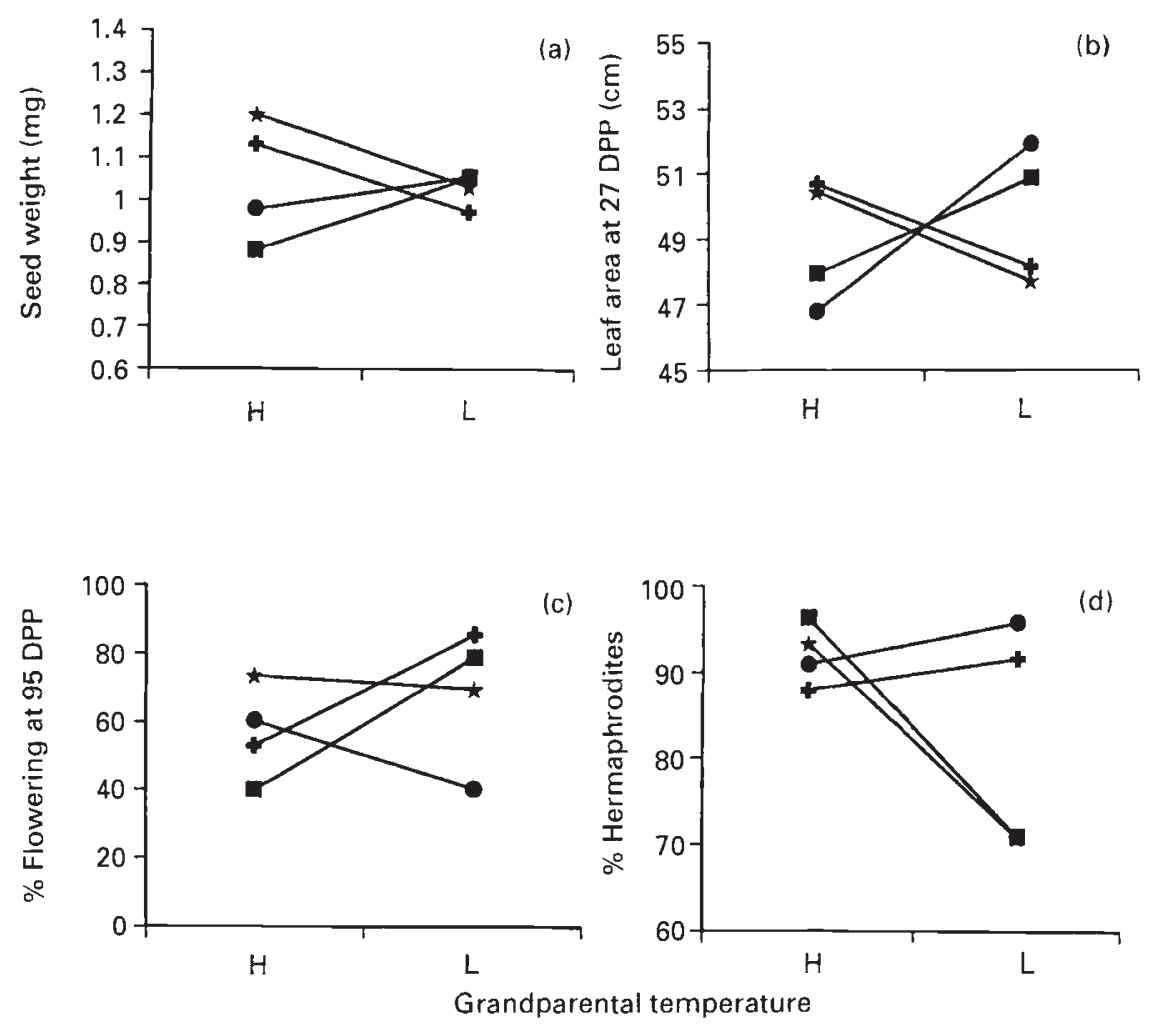

Fig. 2 Genotype-specific responses to grandparental temperature (GPT) for four maternal families (MFAMs) of Plantago lanceolata: (a) mean seed weight; (b) mean leaf area $\left(\mathrm{cm}^{2}\right)$ at 27 dpp; (c) mean per cent plants flowering at $95 \mathrm{dpp}$; (d) mean per cent hermaphroditic plants. Each symbol represents a different MFAM. $\mathrm{H}$, high GPT; L, low GPT.

was associated with higher temperatures; under longer days, the reverse pattern was observed.

\section{Discussion}

Temperature can influence the phenotypic expression of fitness traits for more than one generation in $P$. lanceolata. Below we discuss the strength of these heritable temperature effects, the possible mechanisms of transmission, and their possible evolutionary consequences. We also discuss the role of flowering time in producing parental effects in natural plant populations. Natural differences in flowering phenology can produce parental effects in $P$. lanceolata.

\section{Grandparental temperature effects}

Most parental effects that Lacey (1996) detected in the second generation carried over in some form to the third generation (Table 4). Averaged over MFAMs, GPT affected leaf area and allometry and onset of flowering by 7 per cent, 9 per cent, and 16 per cent, respectively. The GPT effect decreased from the second to the third generation for flowering, but was similar in both generations for leaf area. Low GPT accelerated flowering in both generations. Significant and large GPT $\times$ MFAM interactions were detected for seed weight, leaf area, onset of flowering and male sterility. The only trait to show no main or interaction effect of GPT was germination.

The GPT effects were most probably caused by differences in postzygotic temperature, i.e. differences during fertilization and early embryonic development of the parental generation. The reason is that postzygotic temperature influenced the second generation more strongly than did prezygotic temperature (Lacey, 1995). Heritable environmentally induced parental effects have been detected in a few plant species when pre- and postzygotic effects were combined (Durrant, 1962; Alexander \& Wulff, 1985; Miao et al., 1991a,b; Schneeberger \& Cullis, 1991; Wulff \& Bazzaz, 1992; Platenkamp \& Shaw, 1993). Our results suggest that postzygotic effects, when considered separately, are heritable.

Phenotypic changes in $P$. lanceolata were manifested more often in adult traits than in juvenile traits. The life cycle of plants like $P$. lanceolata moves gradually through juvenile and adult phases. Increasingly, biologists are finding that heritable phenotypic effects do extend into the adult phase (Alexander \& Wulff, 1985; Miao et al., 1991a,b; Purrington, 1993; Lacey, 1996). Our data show that 


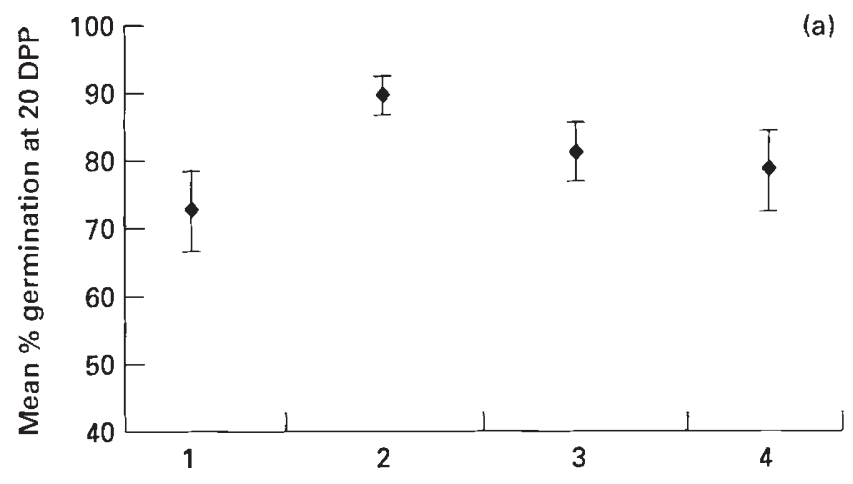

(b)
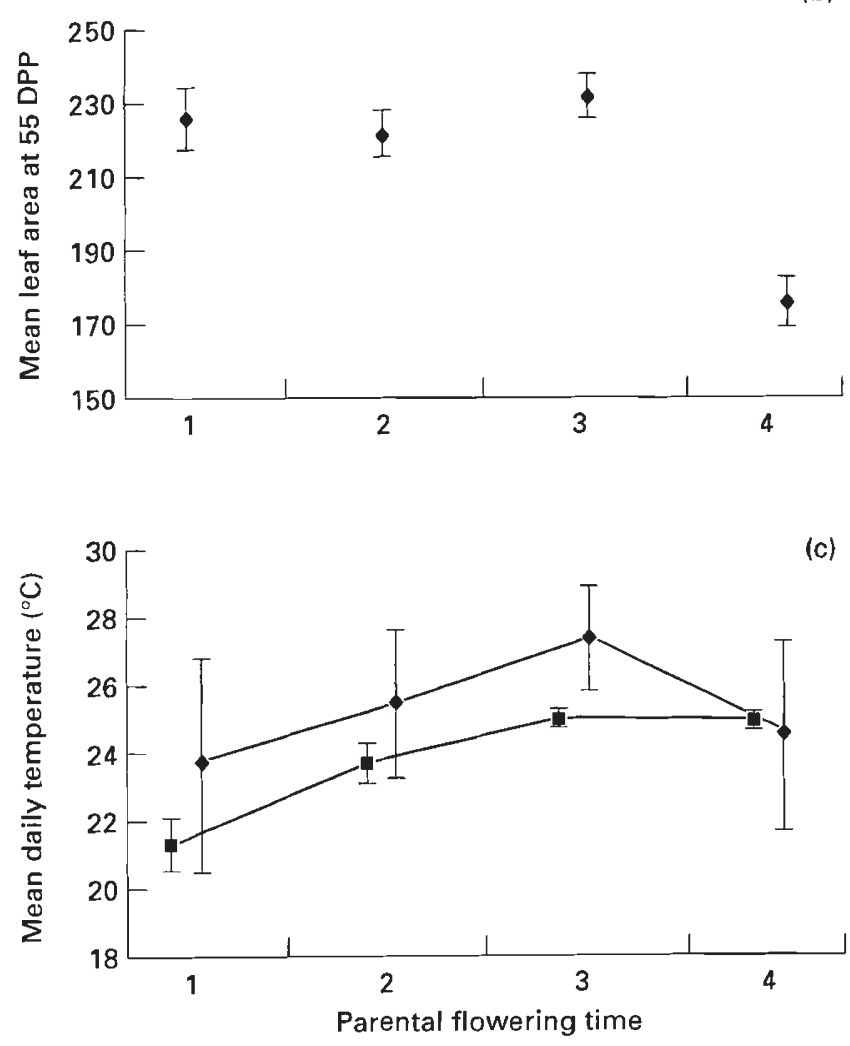

Fig. 3 Effects of parental flowering time (PFT) in Plantago lanceolata on offspring (a) mean leaf area $\left(\mathrm{cm}^{2}\right)$ and (b) mean per cent germination. PFT treatments: $1=$ May 22, 2 = June $12,3=$ July 3, and $4=$ July 24 . (c) Mean daily temperatures for 3 weeks following transplantation shown for each PFT treatment in $1991(\diamond)$ and averaged over 30 years ( $\mathbf{\square}$. Mean monthly temperatures for May, June and July averaged over the years 1961-1990 were $18.8^{\circ} \mathrm{C}, 22.8^{\circ} \mathrm{C}$ and $24.9^{\circ} \mathrm{C}$, respectively. Vertical lines represent $\pm 1 \mathrm{SE}$.

for some adult traits (leaf area, allometry, and onset of flowering) this heritable parental effect is at least partially independent of phenotypic correlations between juvenile and adult traits.
The heritable GPT effects are more likely explained by differential gametophytic selection or genetic change induced by the environment. An environment could theoretically produce an intergenerational effect in at least three ways: first, through gametophytic selection, typically not detected until the subsequent sporophytic phase of the life cycle, secondly, through modification of the genome, and thirdly, through short-lived nongenetic changes (Lacey, 1996). The latter two mechanisms are equivalent to intergenerational phenotypic plasticity. Short-lived nongenetic changes are less likely to have caused the phenotypic patterns in P. lanceolata. First, the prevailing belief is that nongenetic environmental effects are strongest for seed weight and germination, which are juvenile traits, and wane thereafter (Roach \& Wulff, 1987). We observed that most traits affected were adult rather than juvenile traits. Secondly, nongenetic parental effects are generally thought to disappear by the end of the second generation. Our temperature-induced effects persisted into the third generation. Therefore, if prevailing beliefs are correct, then genome modification or gametophytic selection seem more likely causes. Environmentally induced heritable phenotypic changes have been observed in flax, tobacco, and a few other plant species (Durrant, 1962; Alexander \& Wulff, 1985; Miao et al., 1991a,b; Wulff \& Bazzaz, 1992; Platenkamp \& Shaw, 1993). Also, rapid and heritable genomic changes have been produced by extreme environments, tissue culture, methylation, and hybridization (e.g. Schneeberger \& Cullis, 1991; Matzke \& Matzke, 1993; Dass \& Messing, 1994). Similar changes may have occurred in $P$. lanceolata. Alternatively, temperature may have affected gametophytic fitnesses. Recent studies have shown that the environment can affect many pollen characteristics (e.g. Young \& Stanton, 1990; Lau \& Stephenson, 1993).

Regardless of mechanism, our data suggest that environmentally induced parental effects could facilitate the evolutionary divergence of life history patterns and breeding systems among plant populations. Lacey (1996) argued that such facilitation could occur when changes in some predictable environmental factor, like temperature, are associated with habitat change and when genotypes differ in their response to this factor. Genetic variation in responses to parental environment is a necessary condition for this facilitation. Our experiment shows significant genotypic-specific responses for seed weight, growth, onset of flowering, and male sterility in $P$. lanceolata. All traits are likely to contribute to individual fitness, and for three of them, the respon- 
Table 4 Effects of first generation, pre- and postzygotic temperature, on second (Lacey, 1996) and third generation plants in Plantago lanceolata

\begin{tabular}{|c|c|c|c|}
\hline \multirow[b]{2}{*}{ Trait } & \multicolumn{2}{|c|}{ 2nd Generation } & \multirow{2}{*}{$\begin{array}{l}\text { 3rd Generation } \\
\text { (Grandparental) }\end{array}$} \\
\hline & (Pre-zygotic) & (Post-zygotic) & \\
\hline \multicolumn{4}{|c|}{ (a) Main effects of temperature } \\
\hline Seed weight & No & Yes & No \\
\hline Germination & Yes & Yes & No \\
\hline Early growth & Yes & Yes & $\begin{array}{l}\text { No at } 27 d p p \\
\text { Yes at } 55 d p p\end{array}$ \\
\hline Onset of flowering & Yes & Yes & Yes \\
\hline Leaf allometry & - & - & Yes \\
\hline Male sterility & - & - & No \\
\hline \multicolumn{4}{|c|}{ (b) Genotype $\times$ environment interactions } \\
\hline Seed weight $(P=0.057)$ & No & - & Yes \\
\hline Germination & Yes & - & No \\
\hline Early growth & Yes & - & Yes \\
\hline Onset of flowering & No & - & Yes \\
\hline Leaf allometry & - & - & No \\
\hline Male sterility & - & - & Yes \\
\hline
\end{tabular}

Statistically significant effects are indicated by a 'yes'. A $P$-value is shown for a marginal effect. Dashes indicate that no data were collected.

ses were large (Fig. 2). MFAMs that differed little in seed weight at low GPT differed by 36 per cent at high GPT. Low GPT produced a 25 per cent increase in male sterility in two MFAMs but not in the others. The percentage of plants flowering by day 94 in some MFAMs was double that in other MFAMs and in both GPT treatments. For all traits, the rank order of MFAMs changed with GPT. Thus, families showed large differences in their response to GPT, which suggests that plantain populations living in different temperature regimes, e.g. as might arise from altitudinal or latitudinal change, could evolve in different directions because of parental temperature effects alone. Additionally, the rates of evolutionary change could differ among habitats because of differences in interfamily variance for fitness traits, e.g. male sterility (Fig. 2d), across temperature regimes.

Our data suggest caution when using fieldcollected data to evaluate theoretical models about the evolution of gynodioecy. Van Damme (1983) suggested that male sterility is plastic in $P$. lanceolata, and our results demonstrate this for some families. Low temperature enhances femaleness in many diclinous species (Chailakhyan \& Khrianin, 1987). Our data show that this temperature effect is heritable across at least one generation. Thus, male sterility could differ among natural populations because of intra- and intergenerational temperature effects.

\section{Parental flowering time effects}

Our experiment provides additional evidence that natural environmental variation can produce parental effects. Parental flowering time affected offspring germination and growth in plantains, even when controlling for parental family, age, nutrient, water and light availability and when reducing possible confounding effects of paternal genotype. Seasonal changes in temperature were not responsible for PFT effects. Given the higher than average and less variable temperatures across PFT treatments in 1991, this absence is not surprising. The realized temperature variation for all PFT treatments fell within the range of temperatures used for the high GPT treatment alone.

Seasonal changes in photoperiod may explain the phenotypic differences in germination. Increasing day length (in both PFT 2 and 3 treatments) significantly increased offspring germination. Greenhouse studies have shown that photoperiod can affect germination in some species (e.g. Gutterman, 1983). Our data suggest that natural variation in photoperiod affects germination.

Most studies of environmentally induced effects in 
plants have been conducted entirely in greenhouses or growth chambers. [Exceptions are those of Bière (1991) and Schmitt et al. (1992).] In these artificial settings, the environmental variation often differs from or exceeds the variation that a plant encounters in the field. Ultimately, if we are to evaluate the importance of parental effects in the evolution of life history patterns and breeding systems in natural plant populations, then we will need to focus our attention on measuring these effects in natural settings.

\section{Acknowledgements}

We thank S. Barrett and M. Pigliucci for comments on a draft of this paper, D. Herr and M. Skinner for statistical assistance, the Duke University Phytotron and the North Carolina A and T State University Experimental Farm for assistance with growing plants, and the National Weather Service for the temperature data. Work was funded by NSF grants BSR-8717663 to E.P.L. and BSR-8706429 to the Duke University Phytotron, and by a UNCG undergraduate research grant to A.L.C.

\section{References}

ALEXANDER, H. M. AND WULFF, R. D. 1985. Experimental ecological genetics in Plantago X. The effects of maternal temperature on seed and seedling characters in $P$. lanceolata. J. Ecol., 73, 271-282.

ANTONOvics, J. AND SCHMiTT, J. 1986. Paternal and maternal effects on propagule size in Anthoxanthum odoratum. Oecologia, 69, 277-282.

BIĖRE, A. 1991. Parental effects in Lychnis flos-cuculi. II: selection on time of emergence and seedling performance in the field. J. Evol. Biol., 4, 467-486.

CHAILAKHYAN, M. K. AND KHRIANIN, v. N. 1987. Sexuality in Plants and its Hormonal Regulation. Springer-Verlag, New York.

DAS, O. P. AND MESSING, J. 1994. Variegated phenotype and developmental methylation changes of a maize allele originating from epimutation. Genetics, 136, 1121-1141.

DURRANT, A. 1962. The environmental induction of heritable change in Linum. Heredity, 17, 27-61.

GUTTERMAN, Y. 1983. Flowering, seed development, and the influences during seed maturation on seed germination of annual weeds. In: Duke, S. O. (ed.) Weed Physiology. Vol. 1. Reproduction and Ecophysiology, pp. 1-25,
CRC Press, Boca Raton, Florida.

LACEY, E. P. 1996. Parental effects in Plantago lanceolata. L. I. A growth chamber experiment to examine preand post-zygotic temperature effects. Evolution (in press).

LAU, T. C. AND STEPHENSON, A. G. 1993. Effects of soil nitrogen on pollen production, pollen grain size, and pollen performance in Cucurbita pepo (Cucurbitaceae). Am. J. Bot., 80, 763-768.

MATZKE, M. AND MATZKE, A. J. M. 1993. Genomic imprinting in plants: parental effects and trans-inactivation phenomena. Ann. Rev. Pl. Physiol. Pl. Mol. Biol. 44, 53-76.

MIAO, S. L., BAZZAZ, F. A. AND PRIMACK, R. B. 1991a. Effects of maternal nutrient pulse on reproduction of two colonizing Plantago species. Ecology, 72, 586-596.

MIAO, S. L., BAZZAZ, F. A. AND PRIMACK, R. B. $1991 \mathrm{~b}$. Persistence of maternal nutrient effects in Plantago major: the third generation. Ecology, 72, 1634-1642.

PlateNKAMP, G. A. J. AND SHAw, R. G. 1993. Environmental and genetic maternal effects on seed characters in Nemophila menziesii. Evolution, 47, 540-555.

PURrington, c. B. 1993. Parental effects on progeny sex ratio, emergence, and flowering in Silene latifolia (Caryophyllaceae). J. Ecol., 81, 807-811.

ROACH, D. A. AND WULFF, R. D. 1987. Maternal effects in plants. Ann. Rev. Ecol. Syst., 18, 209-235.

Ross, M. D. 1973. Inheritance of self-incompatibility in Plantago lanceolata. Heredity, 30, 169-176.

SAS InSTITUTE. 1985. SAS User's Guide: Statistics, version 5. SAS Institute Inc., Cary, NC.

SCHMITT, J., NILES, J. AND WULFF, R. D. 1992. Norms of reaction of seed traits to maternal environments in Plantago lanceolata. Am. Nat., 139, 451-466.

SCHNEEBERGER, R. G. AND CULL1S, C. A. 1991. Specific DNA alterations associated with the environmental induction of heritable changes in flax. Genetics, 128, 619-630.

TERAMURA, A. H., ANTONOViCs, J. AND STRAIN, B. R. 1981. Experimental ecological genetics in Plantago IV. Effects of temperature on growth rates and reproduction in three populations of Plantago lanceolata L. (Plantaginaceae). Am. J. Bot., 68, 425-434.

VAN DAMME, J. M. M. 1983. Gynodioecy in Plantago lanceolata L. II. Inheritance of three male sterility types. Heredity, 50, 253-273.

WULFF, R. AND BAZZAZ, F. A. 1992. Effect of the parental nutrient regime on growth of the progeny in Abutilon theophrasti (Malvaceae). Am. J. Bot., 79, 1102-1107.

YOUNG, H. J. AND STANTON, M. L. 1990. Influence of environmental quality on pollen competitive ability in wild radish. Science, 248, 1631-1633. 